\title{
Secretion of flagellin by the LEE-encoded type III secretion system of enteropathogenic Escherichia coli
}

\author{
Luminita Badea ${ }^{1,2}$, Scott A Beatson ${ }^{3}$, Maria Kaparakis ${ }^{1}$, Richard L Ferrero ${ }^{1}$ and \\ Elizabeth L Hartland*2
}

Address: ${ }^{1}$ Department of Microbiology, Monash University, Melbourne, Victoria, Australia, ${ }^{2}$ Department of Microbiology and Immunology, University of Melbourne, Melbourne, Victoria, Australia and ${ }^{3}$ School of Molecular and Microbial Sciences, University of Queensland, Brisbane, Queensland, Australia

Email: Luminita Badea - lbadea@unimelb.edu.au; Scott A Beatson - scott.beatson@uq.edu.au;

Maria Kaparakis - Maria.Kaparakis@med.monash.edu.au; Richard L Ferrero - Richard.Ferrero@med.monash.edu.au;

Elizabeth L Hartland* - hartland@unimelb.edu.au

* Corresponding author

Published: 6 February 2009

BMC Microbiology 2009, 9:30 doi:10.1 186/147|-2180-9-30
Received: 24 September 2008

Accepted: 6 February 2009

This article is available from: http://www.biomedcentral.com/I47/-2/80/9/30

(C) 2009 Badea et al; licensee BioMed Central Ltd.

This is an Open Access article distributed under the terms of the Creative Commons Attribution License (http://creativecommons.org/licenses/by/2.0), which permits unrestricted use, distribution, and reproduction in any medium, provided the original work is properly cited.

\begin{abstract}
Background: Enteropathogenic Escherichia coli (EPEC) is an attaching and effacing (A/E) pathogen that possesses a type III secretion system (T3SS) encoded within the locus of enterocyte effacement (LEE). The LEE is essential for A/E lesion formation and directs the secretion and translocation of multiple LEE-encoded and non-LEE encoded effector proteins into the cytosol of infected cells. In this study we used proteomics to compare proteins exported to the culture supernatant by wild type EPEC E2348/69, a $\triangle$ espADB mutant and a $\triangle$ escF T3SS mutant.
\end{abstract}

Results: We observed that flagellin was consistently and strongly present in the secretome of wild type EPEC and the $\triangle$ espADB mutant but present only weakly in the secretome of the $\triangle$ escF mutant. Given the ancestral relationship between the flagella export apparatus and virulence associated T3SSs, we investigated whether FliC could utilise the LEE-encoded T3SS for export. In the absence of a functional flagella export apparatus, we showed that FliC could be secreted by the LEEencoded T3SS and stimulate (Toll-like receptor 5) TLR5 signalling but could not confer motility.

Conclusion: Since the secretion of FliC during A/E lesion formation would presumably be disadvantageous for the pathogen, we propose that virulence associated T3SSs and flagella T3SSs have evolved through a system of chaperones and complex regulatory pathways to be functional at different times to ensure that FliC secretion does not occur during T3SS effector translocation.

\section{Background}

EPEC is an important cause of infant diarrhea in the developing world and is one of several gastrointestinal pathogens of humans and animals capable of causing distinctive lesions in the gut, termed attaching and effacing (A/E) lesions [1-3]. A/E lesions are manifested by damage to the integrity of the enterocyte cytoskeleton, which involves intimate attachment of the bacteria to the cell surface coincident with the formation of actin rich pedestal-like structures underneath tightly adherent bacteria [4]. A/E lesion formation is mediated by proteins encoded within a large pathogenicity island called the locus of enterocyte effacement (LEE) [5], which is essential for A/E lesion formation and highly conserved among 
A/E pathogens [6,7]. The LEE encodes regulators, a type III secretion system (T3SS), T3SS chaperones as well as secreted translocator and effector proteins $[5,8,9]$. The T3SS itself is a multiprotein needle-like complex evolutionarily related to the flagella apparatus that comprises more than 20 proteins spanning both the inner and outer membranes of the bacterial envelope. The T3SS secretes and translocates virulence effector proteins from the bacterial cytosol directly into the host cell cytoplasm, where the effector proteins facilitate disease development [10]. Structurally the needle complex closely resembles a flagella basal body $[11,12]$, supporting an evolutionary relationship between the flagella export apparatus and T3SSs. However, despite the architectural similarity between the flagella biosynthesis machinery and T3SSs, the structural components of the needle complex share limited sequence similarity with components of the flagella basal body $[12,13]$.

A unique feature of the EPEC LEE-encoded T3SS is the presence of a filamentous structure formed by monomers of EspA that connect the EscF T3SS needle to the pore forming translocation proteins, EspB and EspD $[8,14]$. EspA demonstrates discrete sequence similarity to flagellin in the carboxyl-terminal region of the protein which is predicted with high probability to adopt a coiled-coil conformation $[15,16]$. Similar to the assembly of flagella from the polymerization of monomeric flagellin [17], polymerization of EspA to form filaments depends on coiled-coil interactions between EspA subunits [15]. In addition, it has been shown that EspA subunits are added to the tip of the growing filament in a similar manner to a growing flagellum [18]. Although EspA filament diameter $(120 \AA)$ is smaller than that of flagella $(230 \AA)$, its assembly has a lumen diameter and helical symmetry parameters very similar to those of the flagellar filamentous structure $[13,19,20]$. Despite these structural similarities, to date no functional overlap has been observed between the two protein secretion systems in EPEC. In this study, we observed that FliC was consistently present in the secretome of wild type EPEC E2348/69 or an $\triangle e s p A D B$ mutant of E2348/69 but only weakly present in the secretome of a $\triangle e s c F$ (T3SS) mutant of EPEC E2348/69. We determined that FliC could be secreted by the LEEencoded T3SS of EPEC E2348/69 and that FliC exported in this manner was able to stimulate an inflammatory response via the pathogen-recognition molecule for bacterial flagellin, Toll-like receptor 5 (TLR5).

\section{Results}

\section{Analysis of the EPEC E2348/69 secretome}

The secretome of EPEC E2348/69 is dominated by the presence of the translocators, EspA, EspB and EspD [9,21]. The genes encoding these proteins are located together in the LEE4 operon. To identify less abundant proteins in the
EPEC E2348/69 supernatant, we generated an $\triangle e s p A D B$ mutant and compared the secreted protein profile of this mutant with that of a $\triangle e s c F$ T3SS mutant EPEC ICC171 by two dimensional gel electrophoresis (2-DGE). escF encodes the needle structure of the LEE-encoded T3SS and mutations in $e s c F$ abolish secretion of the translocator and effector proteins [14,22]. An escF mutant was used in preference to $e s c N$, which encodes the T3SS ATPase, as an $e s c N$ mutant showed greater cell lysis in culture during growth in hDMEM (data not shown). However some cell breakdown was still observed for ICC171 which may account for some spots visualized by 2-DGE (Fig. 1). Both the $\Delta e$ pADB mutant and ICC171 were grown in HEPES buffered DMEM (hDMEM) pH 7.4-7.7 to an $\mathrm{OD}_{600}$ of 1.0 to induce expression of the LEE T3SS. Cultures $(20 \times 5 \mathrm{ml})$ were pooled to control for variations in growth and supernatant proteins were collected by trichloroacetic acid (TCA) precipitation. Following 2-DGE, consistent and dominant spots were excised for tryptic in-gel digestion and MALDI-TOF mass spectrometry analysis. Since the genome sequence of EPEC E2348/69 was not yet annotated, peptide mass fingerprints were analyzed against a limited library of open reading frames from EPEC E2348/ 69 http://www.sanger.ac.uk/Projects/Microbes. As expected, the autotransporter EspC was present in the supernatant of both the $\triangle e s p A D B$ mutant and ICC171. Although we did not identify any non-LEE encoded effector proteins using this approach, we did find that FliC was present abundantly in the supernatants of the $\triangle e s p A D B$ mutant (Fig. 1) and wild-type EPEC (data not shown) but was greatly reduced in the supernatant of the $\Delta e s c F$ mutant, ICC171 (Fig. 1). This was unexpected as previous studies have reported that EPEC flagellation and motility is down regulated by growth in DMEM $[23,24]$. In addition, we observed that FimA export was upregulated in the $\triangle e s p A D B$ mutant. Although we did not investigate the basis for increased FimA protein, fimA is know to be coregulated with flagella biosynthesis in E. coli [25]. Thus increased FimA production and export may be connected to increased FliC production and export. Unfortunately, we were not able to identify any further protein spots by MALDI-TOF analysis other than FimA, EspC and FliC.

\section{The LEE-encoded T3SS promotes flagellin export}

The reduced amount of FliC in the supernatant of ICC171 grown in hDMEM but not the $\triangle e s p A D B$ mutant suggested that either flagellin synthesis and/or export was connected to expression of the LEE-encoded T3SS, since both mutants contain a functional flagella biosynthesis locus, or perhaps that the inactivation of espD led to increased FliC expression which has been reported previously $[23,24]$. To examine the association between the presence of a functional LEE-encoded T3SS and flagellin synthesis and export in hDMEM, we used mono-specific anti-H6 FliC antibodies and immunoblotting to examine the pro- 


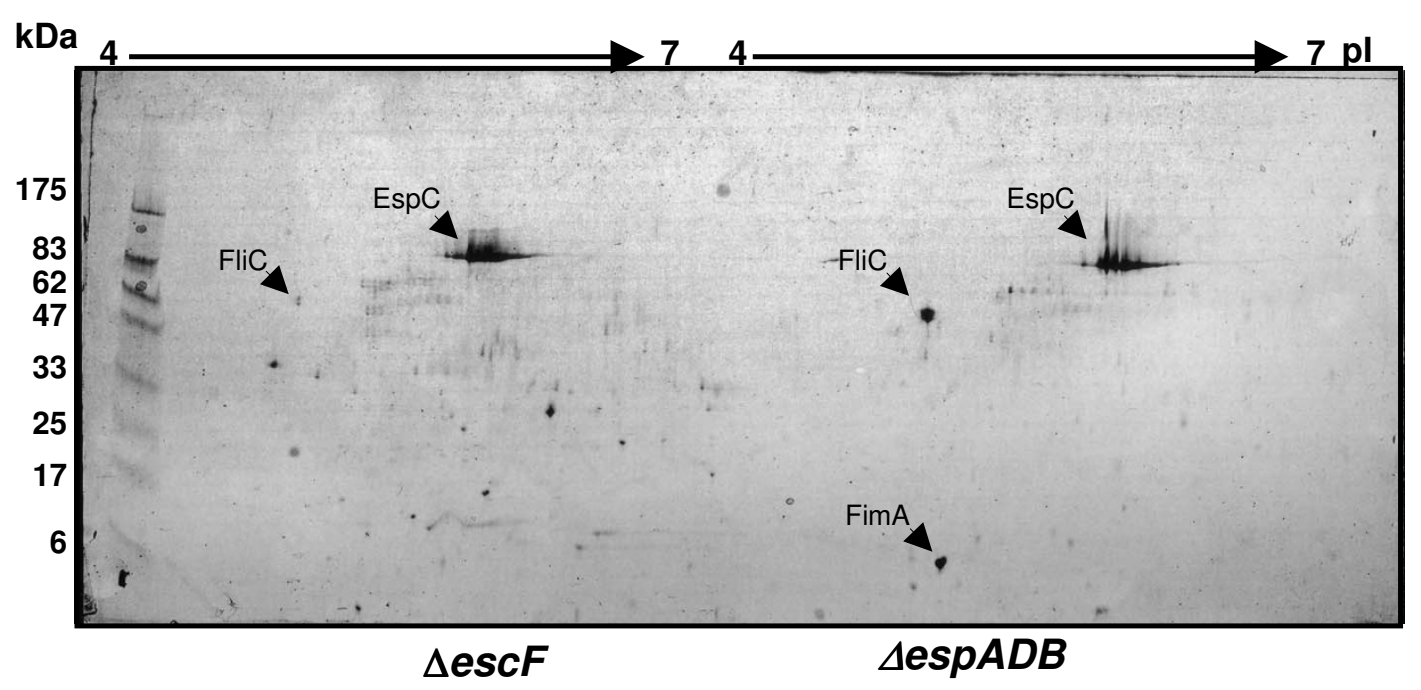

\section{Figure I}

Comparative 2-DGE analysis of the secretomes of EPEC E2348/69 derivatives, ICC I 7I $\triangle$ escF and $\triangle$ espADB. Protein secretion was induced by growth of the culture to $\mathrm{OD}_{600} \mathrm{I.0}$ in hDMEM. Protein size markers are shown in kDa and $\mathrm{pl}$ values (IPG strips of 4-7) are indicated. Identified proteins are labeled with arrows.

duction and secretion of FliC into the culture supernatant by various derivatives of EPEC. Initially we confirmed that FliC secretion in hDMEM by ICC171 was reduced compared with EPEC E2348/69 and the $\triangle e s p A D B$ mutant (Fig. 2 ). To determine if secretion could occur in the absence of a functional flagella biosynthesis apparatus, we inactivated fliI which encodes the flagella system ATPase essential for FliC export by this pathway [26]. Although the results showed that FliC was not found in the supernatant of the $\Delta$ fli mutant grown in hDMEM (Fig. 2), a band corresponding to FliC was also not present in whole cell lysates preparations suggesting that mutation of fliI also abrogated expression of FliC (Fig. 2). In addition, we observed a reduction in the production of FliC by the escF mutant grown in hDMEM (Fig. 2). These data are consistent with previous reports that $f l i C$ expression is down regulated if the protein is not exported [27]. When EPEC derivatives were grown in LB which promotes motility and down regulation of the LEE-encoded T3SS, FliC was produced and exported by all strains except the fliI mutant (Fig. 2). This indicated that mutation of escF did not affect fliC expression and FliC export under conditions that promote flagellation and motility but suggested that under conditions favoring expression of the LEE-encoded T3SS, $e s c F$ was needed for FliC synthesis and/or export.

\section{Secretion of flagellin via the LEE-encoded T3SS of EPEC E2348/69}

To define further the relationship between FliC secretion in hDMEM and expression of the LEE T3SS, we expressed fliC from an IPTG inducible promoter in the expression vector, pTrc99A to overcome the negative feedback inhibition of FliC production in the fliI and escF mutants observed earlier. This plasmid was termed pFliC. A $\Delta f l i C$ mutant was constructed to serve as a control strain and inducible expression and successful secretion of FliC was demonstrated from pFliC $30 \mathrm{~min}$ after induction with IPTG (Fig. 3). An analysis of culture supernatants for the presence of the cytoplasmic protein, DnaK, showed that overexpression of FliC from pFliC did not result in increased cell lysis (Fig. 3).

To investigate the contribution of the LEE-encoded T3SS and the flagella secretion system to FliC export in hDMEM, we constructed a $\triangle$ fliI/escF double mutant where both the LEE-encoded and flagella secretion systems were inactivated. pFliC was introduced into the $\Delta f l i C, \Delta f l i I$ and $\Delta$ fliI/escF mutant strains and immunoblotting of whole cell lysates showed that FliC expression was successfully induced (Fig. 4). We then examined the supernatants of the $\Delta f l i$ and $\Delta f l i I / e s c F$ mutants carrying pFliC for secretion of FliC after induction with IPTG for $30 \mathrm{~min}$. Secretion of FliC was detected in supernatants derived from the $\Delta f l i$ mutant but was greatly reduced in the $\Delta f l i I / e s c F$ mutant (Fig. 4). To verify that a functional LEE T3SS was required for FliC secretion when the flagella export system was inactivated, we complemented the $\Delta f l i I / e s c F$ mutant with pFliCEscF. Immunoblot analysis of supernatant proteins showed that flagellin export was partially restored to the $\Delta f l i I / e s c F$ mutant upon trans-complementation with escF (Fig. 4). The success of trans-complementation with escF was also confirmed by performing a fluorescence actin 


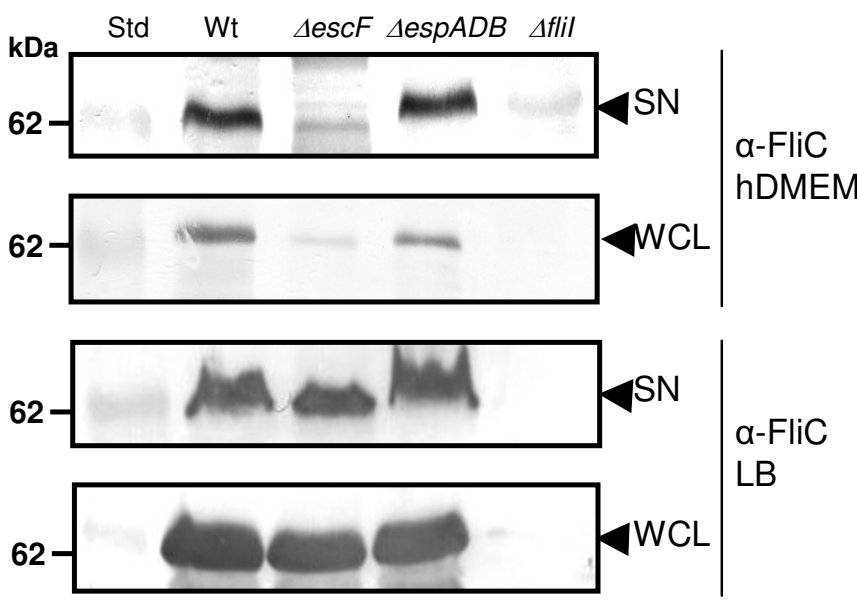

Figure 2

Immunoblot analysis of secreted proteins in the culture supernatant (SN) and whole cell lysates (WCL) prepared from derivatives of EPEC E2348/69 grown in hDMEM and LB. Arrows indicate a reactive band corresponding to FliC detected with anti-H6 FliC antibodies.

staining (FAS) test (data not shown). Therefore, in the absence of a functional flagella secretion apparatus (due to inactivation of fliI), FliC export still occurred if the LEEencoded T3SS was intact. The involvement of the flagellin chaperone, FliS, in FliC secretion by the LEE-encoded T3SS was examined by constructing a double $\Delta$ fliI/flis mutant. Flagellin expressed from pFliC was secreted by the $\Delta$ fliI/fliS mutant in equivalent amounts to $\Delta f l i$ (pFliC) suggesting that the FliS chaperone was not involved in LEE-dependent FliC secretion (data not shown). To determine whether FliC was recognized as an effector or a translocator by the LEE-encoded T3SS, we also examined FliC export by a sepL mutant. The mutation of sepL leads to preferential secretion of effectors and reduced secretion of translocators $[28,29]$. We found that the sepL mutant secreted flagellin in equivalent amounts to the $\triangle e s p A D B$ mutant suggesting that FliC was recognized as an effector of the LEE-encoded T3SS (data not shown).

\section{Flagellin exported by the LEE T3SS induces NF-kappa B activity but does not confer motility}

Previous work has shown that FliC from EPEC E2348/69 can stimulate proinflammatory cytokine production through TLR5 signaling [30]. Indeed, EPEC H6 flagellin is a potent activator of interleukin- 8 release in T84 and HT29 intestinal epithelial cells [24,31]. Here we investigated host cell signaling in response to EPEC E2348/69 flagellin by measuring NF-kappa B activation in human embryonic kidney HEK293 cells using an NF-kappa B dependent luciferase reporter assay. Since HEK293 cells possess functional TLR5 and non-functional forms of TLR2 and TLR4, the cell line is most likely responsive only to flagellin and not to Gram-negative lipoproteins and lipopolysaccha- ride [32]. As expected, there was a correlation between the presence of FliC in the bacterial culture supernatant and NF-kappa B activation (Fig. 5). Although the activation of NF-kappa B by wild type EPEC E2348/69 supernatant proteins (Fig. 5B) appeared lower than strains producing the same amount of FliC (Fig. 5A), the western blot presented represented one experiment only and NF-kappa B activation was performed more than three times using different preparations of supernatant proteins. Despite batch to batch variation in supernatant protein preparations, the results of mean NF-kappa B activity showed that FliC present in the culture supernatant of the $\Delta$ fli mutant carrying pFliC could stimulate a 5 fold greater increase in NFkappa B activity compared to the $\Delta$ fliI/escF mutant carrying pFliC $(P=0.0042$, unpaired two tailed $t$-test $)$. As expected, the fliI mutant derivatives of EPEC E2348/69 secreting FliC via the LEE-encoded T3SS were non-motile (Fig. 5C), due to the absence of an intact flagella export apparatus.

\section{Discussion}

Many Gram-negative pathogens utilize a T3SS to deliver diverse effector proteins directly into eukaryotic cells. The structure of the T3SS apparatus is conserved among different pathogens and shares structural similarity with the flagella basal body. The reported ancestral relationship between the two secretion systems is based on low sequence similarity between some components as well as functional conservation [33]. Under certain conditions, virulence effector proteins may be secreted, but not translocated by the flagella T3SS [34-37]. The preferential secretion of effector proteins by their cognate T3SS rather than the flagella export apparatus depends largely on a 


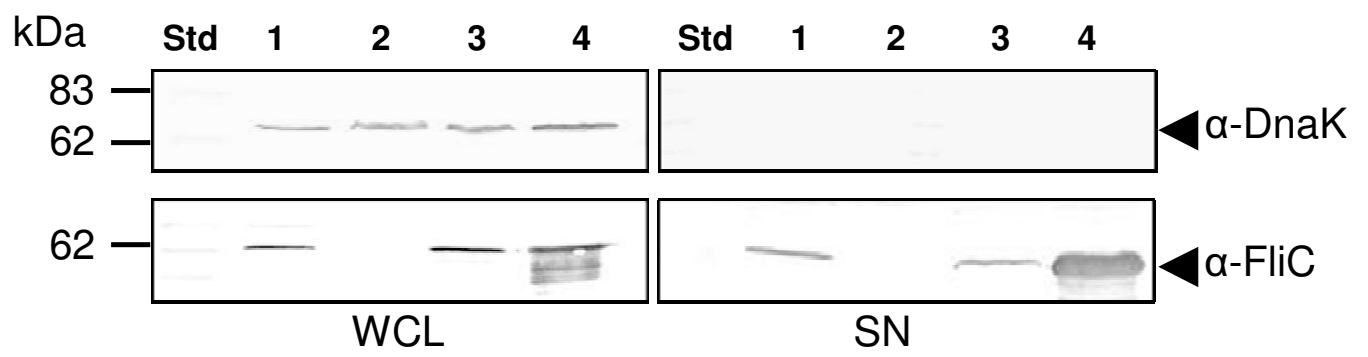

Figure 3

Immunoblot analysis of secreted proteins (SN) and whole cell lysates (WCL) prepared from derivatives of EPEC E2348/69 grown in hDMEM. Lane I: E2348/69; lane 2: $\Delta$ fliC; lane 3: $\Delta$ fliC (pFliC) non-induced; lane 4: $\Delta$ flil (pFliC) induced with I mM IPTG for $30 \mathrm{~min}$. Arrows indicate position of a reactive band corresponding to FliC detected with anti-H6 FliC antibodies or DnaK detected with anti-DnaK antibodies.

system of chaperones that confer pathway specificity. In Salmonella enterica serovar Typhimurium, truncated forms of the effectors SptP and SopE that lack the chaperone binding domain for secretion by the T3SS are instead secreted by the flagella export apparatus $[35,38]$. This suggests that not only do the T3SS system chaperones confer pathway specificity, but also that the flagella export system is the default secretion pathway for unchaperoned proteins [35].

Recently, Miao et al (2006) showed that flagellin from $S$. Typhimurium present in the cytosol of infected macrophages stimulated IL1- $\beta$ release in macrophages through activation of the intracellular NACHT-leucine-rich repeat protein, Ipaf. The activation of Ipaf by cytosolic flagellin was dependent on the SPI1-encoded T3SS and not the flagella biosynthesis locus [39]. The authors suggested that flagellin secretion most likely occurred via the SPI1 T3SS needle complex and concluded that the accidental export of flagellin into the host cell by the SPI1 T3SS may provide an advantage to the host through the stimulation of pro-inflammatory cytokine expression and release [39]. In this study, we also detected the secretion of flagellin by EPEC in the absence of a functional flagella export apparatus that was largely dependent on the LEE-encoded T3SS and this indiscriminate secretion of flagellin had the potential to stimulate NF-kappa B activity. However, we were not able to visualize FliC in the intracellular environment of the host cell using immunofluorescence to compare FliC staining in permeabilized and nonpermeabilized HeLa cells infected with EPEC (data not shown). This suggested that in contrast to the SPI1encoded T3SS of Salmonella, the LEE-encoded T3SS of EPEC did not translocate flagellin into the host cell. It remains possible however, that the method used here to visualize intracellular flagellin was not sensitive enough to detect small amounts of translocated FliC protein.

\section{Conclusion}

We conclude that the flagella and LEE-encoded T3SSs of EPEC have undergone selection to evolve temporal differences in expression and specificity of function through a system of chaperones and regulatory checks that maintain mutually exclusive export of the T3SS effectors and flagellin. The fact that EPEC infection does not result in a strong inflammatory response suggests that there has been strong evolutionary selection against TLR5 activation during A/E lesion formation [40]. Indeed, despite the structural similarity between EspA and FliC, EspA lacks the major D0 domain that activates TLR5 signaling by FliC [41]. The dedicated function of the respective virulence-associated and flagella T3SSs to the secretion of their cognate substrates is likely to be critical in ensuring that flagellin is not accidentally released during the important initial stages of infection where it may prematurely activate inflammatory signaling pathways.

\section{Methods}

\section{Bacterial strains, cell lines and growth conditions}

The bacterial strains used in this study are listed in Table 1. E. coli strains were grown overnight at $37^{\circ} \mathrm{C}$ in Luria Bertani (LB) broth followed by culturing in $25 \mathrm{mM}$ HEPES-buffered DMEM with $44 \mathrm{mM} \mathrm{NaHCO}_{3}$ (hDMEM). HeLa cells and HEK293 cells were cultured at $37^{\circ} \mathrm{C}$ in the presence of $5 \% \mathrm{CO}_{2}$ in DMEM supplemented with $10 \%$ FCS and $2 \mathrm{mM}$ glutamine. Where necessary the following antibiotics were supplied at the following final concentrations: kanamycin $(100 \mu \mathrm{g} / \mathrm{ml})$, chloramphenicol $(25 \mu \mathrm{g} /$ $\mathrm{ml})$ and ampicillin $(100 \mu \mathrm{g} / \mathrm{ml})$.

\section{Isolation of secreted proteins}

EPEC was inoculated into $5 \mathrm{ml}$ of LB and grown overnight at $37^{\circ} \mathrm{C}$ with shaking. EPEC was routinely diluted 1:100 in DMEM containing $44 \mathrm{mM} \mathrm{NaHCO}$ buffered with 25 $\mathrm{mM}$ HEPES and grown at $37^{\circ} \mathrm{C}$ with shaking. Bacterial 


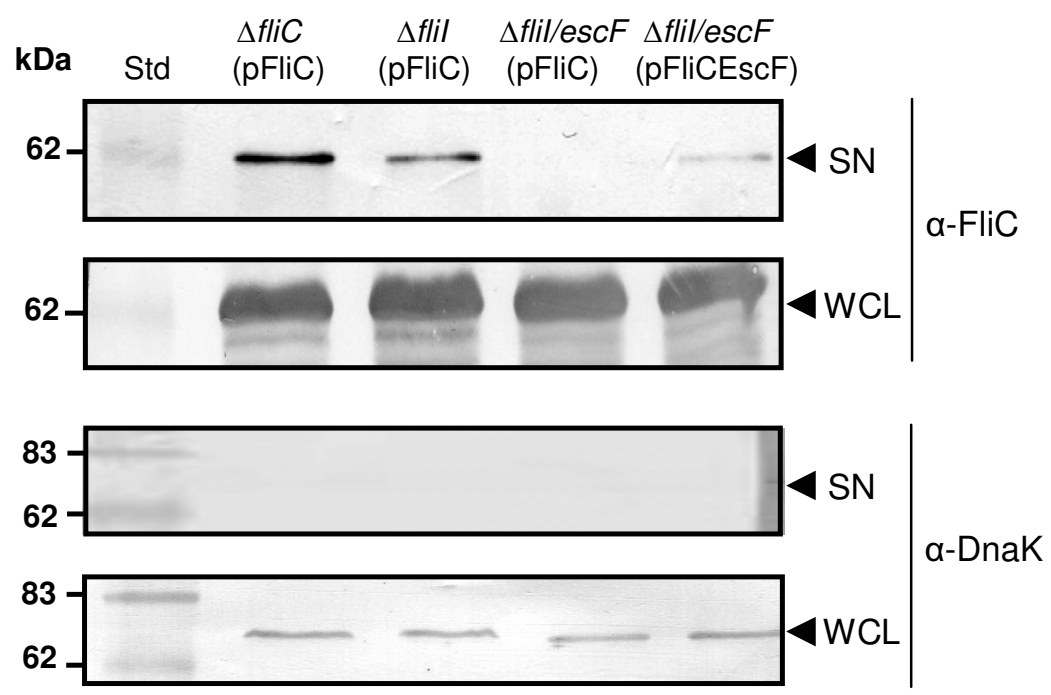

\section{Figure 4}

Immunoblot analysis of secreted proteins (SN) and whole cell lysates (WCL) prepared from derivatives of EPEC E2348/69 grown in hDMEM. Arrows indicate position of a reactive band corresponding to FliC detected with anti$\mathrm{H} 6 \mathrm{FliC}$ antibodies or DnaK detected with anti-DnaK antibodies. FliC expression was induced in vitro with I mM IPTG from the trc promoter in PTrc99A.

supernatants were analyzed at mid- to late-log phases of growth [42]. To ensure removal of bacteria and cellular debris, the bacterial supernatants were filtered through $0.45 \mu \mathrm{m}$ pore filters (Millipore, Bedford, MA) [43]. The cell-free supernatants were precipitated with a final $10 \%$ $\mathrm{w} / \mathrm{v}$ trichloroacetic acid (TCA) solution and subsequent centrifugation at $13,000 \mathrm{rpm}$ for $45 \mathrm{~min}$ at $4{ }^{\circ} \mathrm{C}$ followed by three methanol washes. Equal amounts of proteins were analyzed by SDS-PAGE and by two-dimensional gel electrophoresis. Proteins of interest were subjected to mass spectrometry.

\section{SDS-PAGE and immunoblotting}

The bacterial suspensions were adjusted to an absorbance of 1.0 at $\mathrm{OD}_{600}$. Equal numbers of bacteria were used to prepare whole cell extracts in sample denaturation buffer and separated by 12\% SDS-PAGE. The gels were stained with Coomassie Brilliant Blue R-250 (Bio-Rad, Hercules, CA) or transferred onto nitrocellulose membranes (Pall Life Science, Pensacola, FL) for immunoblotting. The immobilized proteins were incubated with primary antibodies against H6 flagellin (Statens Serum Institut, Denmark) or cytoplasmic protein DnaK (Assay Designs, Ann Arbor, MI) followed by incubation with goat anti-rabbit (Sigma, St. Louis, MO) or sheep anti-mouse IgG (Chemicon, Melbourne, Australia) conjugated to alkaline-phosphatase. Antibody binding was detected with chemiluminescent reagent (Astral Scientific, Gymea, NSW, Australia).

\section{Two-dimensional Gel Electrophoresis}

Proteins secreted from approximately $10^{9}$ cells $(\sim 120 \mu \mathrm{g})$ were precipitated with a final $10 \% \mathrm{w} / \mathrm{v}$ TCA solution and material was resuspended in $460 \mu \mathrm{l}$ of following sample solution: $5 \mathrm{M}$ urea (Amersham Pharmacia Biotech, Sweden), $2 \mathrm{mM}$ tributylphosphine (TBP) 2\% CHAPS, 2\% (v/ v) carrier ampholytes (Bio-Rad, CA, USA), 2\% SB 3-10 or 2\% SB 4-7 and trace of bromophenol blue (Pharmacia Biotech) by vortexing [44]. Insoluble material was removed by centrifugation at $12000 \times g$ for $10 \mathrm{~min}$. The $460 \mu \mathrm{l}$ samples were used to passively rehydrate $\mathrm{pH} 3-10$ or $\mathrm{pH}$ 4-7 immobilized $\mathrm{pH}$ gradient dry strips for $18 \mathrm{~h}$ at room temperature (Bio-Rad). Isoelectric focusing was performed using a step-wise protocol with a final voltage of $3500 \mathrm{~V}$ on a Multiphor II (Amersham Pharmacia Biotech, Uppsala, Sweden) equaling a total of $75 \mathrm{kV} \mathrm{h}$. The second dimension was performed on 12\% SDS-PAGE gels using a Protean II Multi-Cell (Amersham Pharmacia). The gels were stained with Colloidal Coomassie Blue G-250 or Sypro Ruby (Molecular Probes, Eugene, OR). Protein samples were isolated from at least three independent preparations of $20 \times 5 \mathrm{ml}$ cultures. More than three separate gels were analyzed for each sample. Protein spots that displayed dominant and consistent patterns were selected for further identification.

\section{Matrix-assisted laser desorbtion/ionization time of flight (MALDI-TOF) mass spectrometry}

Protein spots were excised from gels and washed with 50 $\mathrm{mM}$ ammonium bicarbonate/100\% acetonitrile (60:40 v/ 
A

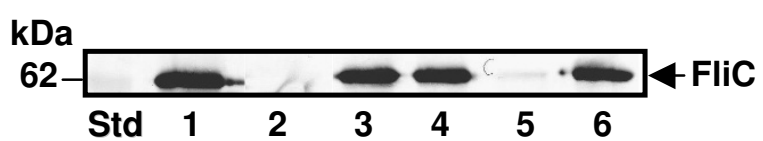

B

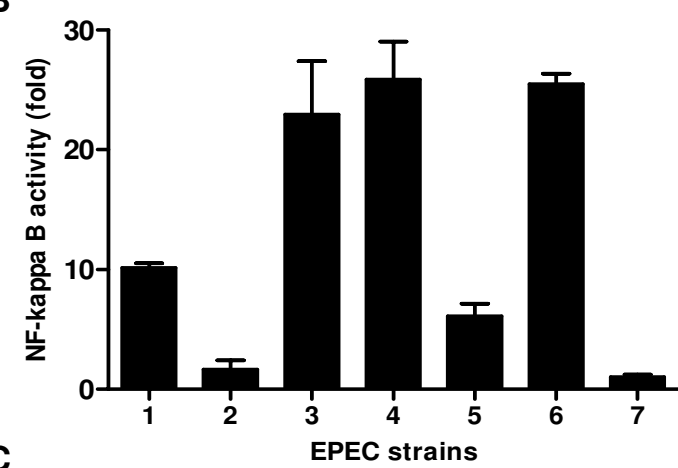

C

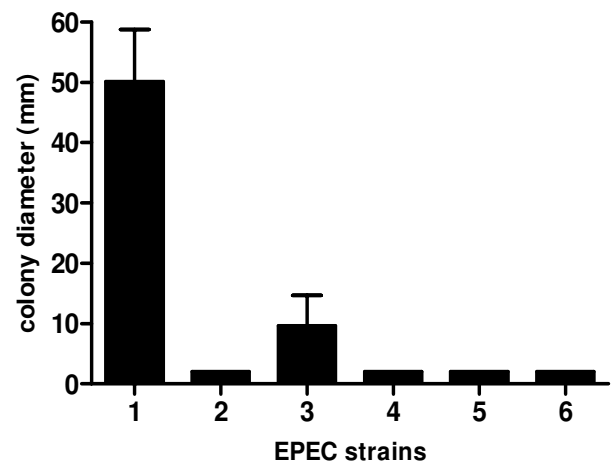

Figure 5

A. Representative immunoblot of secreted proteins prepared from derivatives of EPEC E2348/69 grown in hDMEM and detected with anti-H6 FliC antibodies. Lane I: E2348/69; lane 2: $\Delta$ fliC; lane 3: $\Delta$ fliC (pFliC); lane 4: $\Delta$ flil (pFliC); lane 5: $\Delta$ flil/escF (pFliC); lane 6: $\Delta$ flil/escF (pFliCEscF). B. NF-kappa B-dependent luciferase reporter activity in HEK293 cells stimulated with secreted proteins prepared from derivatives of EPEC E2348/69. I. EPEC E2348/ 69; 2. $\Delta$ fliC; 3. $\Delta$ fliC (pFliC); 4. $\Delta$ flil (pFliC); 5. $\Delta$ flil/escF (pFliC); 6. $\Delta$ flil/escF (pFliCEscF); 7. hDMEM alone. Results are expressed as the mean fold increase \pm SEM with respect to the unstimulated control (fold $=\mathrm{I}$ ) and are representative of three independent experiments performed in triplicate $\mathbf{C}$. Motility of derivatives of EPEC E2348/69 shown in (A) in $0.2 \%$ hDMEM agar. I. EPEC E2348/69; 2. $\Delta$ fliC; 3. $\Delta$ fliC (pFliC); 4. $\Delta$ flil (pFliC); 5. $\Delta$ flil/escF (pFliC); 6. $\Delta$ flil/escF (pFliCEscF).

v). The gel pieces were dried and rehydrated in a solution containing sequencing grade modified trypsin (Promega, Madison, WI) for $1 \mathrm{~h}$ at $4^{\circ} \mathrm{C}$. Excess trypsin solution was removed and the rehydrated gel pieces were immersed in $50 \mathrm{mM}$ ammonium bicarbonate and incubated overnight at $37^{\circ} \mathrm{C}$. Eluted peptides were concentrated and desalted using $\mu-\mathrm{C}_{18}$ Zip-Tips $^{\mathrm{TM}}$ (Millipore Corp., Bedford, MA) and trifluoroacetic acid in acetonitrile solutions. Mass spectra were acquired at the Monash University proteomics facility by Dr. Simon Harris. Lists of mono-isotopic peaks corresponding to various peptides were generated manually. Peptide masses were searched against the NCBInr database by use of the MASCOT software (Matrix Science), with the mass tolerance set to 50 ppm or 200 ppm. Proteins with sequence coverage exceeding $20 \%$ with the matched proteins were considered positive for identification.

\section{Construction of non-polar mutants of EPEC E2348/69}

Non-polar mutations of espADB, fliC, fliI were constructed in EPEC E2348/69 using the $\lambda$ Red recombination system [45]. In addition, double mutants of flilflis and fliIescF were created using alternative antibiotic selection markers. Mutations were obtained using pKD3 as a template with the primer pairs: fliC $_{\Delta} \mathrm{F} /$ fliC $_{\Delta} \mathrm{R}$ and $f l i I_{\Delta} \mathrm{F} /$ fliI $_{\Delta} \mathrm{R}$ and pKD4 as a template with flis $S_{\Delta} \mathrm{F} /$ fliS $_{\Delta} \mathrm{R}$ and espADB ${ }_{\Delta} \mathrm{F} /$ $\operatorname{esp} A D B_{\Delta} \mathrm{R}$ (Table 2 ). The PCR products were digested with DpnI before being electroporated into EPEC E2348/69 carrying the Red Recombinase expression plasmid, pKD46. Mutants were selected on LB plates supplemented with chloramphenicol or kanamycin. All mutations were confirmed by PCR using primers flanking the targeted region (designated "verify", Table 2) and primers within the chloramphenicol or kanamycin resistance gene.

\section{Construction of FliC and EscF expression vectors}

A 1643 bp fragment and a $237 \mathrm{bp}$ fragment containing the fliC and $e s c F$ genes, respectively, were amplified by PCR using primers fliCF and fliCR (fliC) and escFF and escFR $(e s c F)$. Genomic DNA from EPEC E2348/69 was used as a template in PCR (Table 2). The PCR products were digested with NcoI/BamHI and XbaI/HindIII for fliC and $e s c F$, respectively, and ligated into pTrc99A, generating expression vectors pFliC and pFliCEscF. Secretion of flagellin was checked by immunoblotting using anti-H6 antibodies and the function of EscF was confirmed by a fluorescent actin staining (FAS) test on HeLa cells infected with an $e s c F$ mutant carrying pFliCEscF.

\section{Fluorescence actin staining test}

FAS test was performed on infected HeLa cells as described previously [46]. Briefly, EPEC strains were grown overnight at $37^{\circ} \mathrm{C}$ with shaking in LB. Bacteria were added to cells at a dilution factor of 1:50 in DMEM and incubated at $37^{\circ} \mathrm{C}$ for $3-5$ hours. Cells were fixed in $1 \%$ paraformaldehyde, permeabilized with $0.1 \%$ Triton-X 100 (Sigma) and stained with $0.5 \mu \mathrm{g} / \mathrm{ml}$ Phalloidin-TRITC (Sigma). Coverslips were mounted in DAKO fluorescent mounting medium (DAKO Corporation Carpinteria, USA) and stored at $4^{\circ} \mathrm{C}$ in the dark. Samples were examined under 
a 100 × objective using an Olympus, BX51 epifluorescence microscope. Images were acquired using an Olympus DP70 digital camera and merged using DP controller software version 1.1.1.71.

\section{Cell transfection and NF-kappa B luciferase assays}

NF-kappa B luciferase reporter activity in response to the proteins secreted by EPEC strains was determined in HEK293 cells, as described elsewhere [32]. In brief, cells were seeded in 96 well plates (Iwaki, Tokyo, Japan) at $2 \times$ $10^{4}$ cells per well. Each well was transfected with $230 \mathrm{ng}$ of DNA consisting of 60 ng Igkappa-luciferase reporter construct and pCDNA3 complexed with Fugene (Roche, Basel, Switzerand) and made to $100 \mu \mathrm{l}$ with cell culture medium. One day post transfection, the cell culture media was replaced and cells were stimulated for $4 \mathrm{~h}$ with $10 \mu \mathrm{g}$ of TCA precipitated proteins in PBS. At the completion of the HEK293 co-culture experiments, culture media was removed and cells were lysed using reporter lysis buffer (Promega, Madison, WI). Luminescence was measured using a FLUOstar Optima luminometer (BMG Labtech, Offenburg, Germany). All samples were measured in triplicate and all experiments were performed at least three times.

\section{Motility assay}

Freshly grown bacterial colonies were stabbed into motility agar ( $0.2 \%$ agar) plates. The plates were incubated face up at $37^{\circ} \mathrm{C}$ for 16 to $24 \mathrm{~h}$, and motility was assessed by measuring the migration of bacteria through the agar by zone of growth. Results are expressed (in $\mathrm{mm}$ ) as the mean \pm standard deviation of triplicate colonies from 3 independent experiments.

\section{Abbreviations}

EPEC: enteropathogenic E. coli; LEE: locus of enterocyte effacement; T3SS: type III secretion system; A/E: attaching and effacing lesion; TLR: toll-like receptor; SEM standard error of the mean.

\section{Authors' contributions}

LB participated in the design of the study, carried out the experiments and drafted the manuscript. SAB participated in the interpretation of results and writing of the manuscript. MK supervised experiments and participated in writing the manuscript. RLF and ELH participated in the design of the study, the interpretation of results, the writing of the manuscript, the supervision of LB and MK and supplied funding for the project. All authors have read and approved the final manuscript.

\section{Acknowledgements}

We are indebted to Professor Mark Pallen and Sophie Mathews for helpful discussions and advice. We are also grateful to Gad Frankel for the strain, ICCI7I. We gratefully acknowledge Ben Adler, Simon Harris and Paul Cullen at Monash University for their assistance with two-dimensional gel electrophoresis and MALDI-TOF analysis. This work was supported by grants to ELH and RLF from the Australian Research Council and the Australian National Health and Medical Research Council (NHMRC). LB was the recipient of a NHMRC Dora Lush Postgraduate Scholarship. SB was supported by an Australian Research Council (ARC) Australian Research Fellowship.

Table I: Bacterial strains and plasmids used in this study

\begin{tabular}{|c|c|c|c|c|}
\hline Strain/plasmid & Characteristic(s) ${ }^{\mathrm{a}}$ & Motility In DMEM & $\mathbf{F A S}^{\mathrm{b}}$ & Reference \\
\hline \multicolumn{5}{|l|}{ Strains } \\
\hline E2348/69 & Wild type EPEC OI27:H6 & + & + & [47] \\
\hline$|C C I 7|$ & E2348/69 $\Delta \operatorname{esc} F\left(\operatorname{Kan}^{R}\right)$ & $+/-$ & - & {$[14]$} \\
\hline EPEC $\triangle \operatorname{esp} A D B$ & E2348/69 $\triangle \operatorname{espADB}\left(\operatorname{Kan}^{\mathrm{R}}\right)$ & + & - & This study \\
\hline EPEC $\Delta$ flil & $\mathrm{E} 2348 / 69 \Delta f l i\left(\mathrm{Cm}^{\mathrm{R}}\right)$ & - & + & This study \\
\hline EPEC $\triangle$ fliC & E2348/69 $\Delta$ fliC $\left(\mathrm{Cm}^{\mathrm{R}}\right)$ & - & + & Grubman et al, submitted \\
\hline EPEC $\Delta$ flil/escF & E2348/69 $\Delta$ fililescF $\left(\mathrm{Cm}^{\mathrm{R}}, \mathrm{Kan}^{\mathrm{R}}\right)$ & - & - & This study \\
\hline EPEC $\Delta$ flil/flis & $\mathrm{E} 2348 / 69 \Delta$ fili/flis $\left(\mathrm{Cm}^{\mathrm{R}}, \mathrm{Kan}^{\mathrm{R}}\right)$ & & & This study \\
\hline EPEC $\Delta s e p L$ & E2348/69 $\Delta \operatorname{sepL}\left(\operatorname{Kan}^{\mathrm{R}}\right)$ & & & [48] \\
\hline \multicolumn{5}{|l|}{ Plasmids } \\
\hline pKD46 & Red Recombinase helper plasmid $\left(\mathrm{Amp}^{\mathrm{R}}\right)$ & $N \cdot A^{c}$ & N.A & [45] \\
\hline pKD3 & Red Recombinase template plasmid $\left(\mathrm{Cm}^{\mathrm{R}}\right)$ & N.A & N.A & [45] \\
\hline pKD4 & Red Recombinase template plasmid $\left(\operatorname{Kan}^{R}\right)$ & N.A & N.A & {$[45]$} \\
\hline pTrc99A & High-copy number expression vector $\left(\mathrm{Amp}^{\mathrm{R}}\right)$ & N.A & N.A & [49] \\
\hline pFliC & Derivative of pTrc99A encoding fliC from EPEC E2348/69 (AmpR) & N.A & N.A & This study \\
\hline pFliCEscF & $\begin{array}{l}\text { Derivative of } \mathrm{PTr} \text { Tr99A encoding fliC and escF from EPEC E2348/69 } \\
\left(\mathrm{Amp}^{\mathrm{R})} \text {. }\right.\end{array}$ & N.A & N.A & This study \\
\hline pCDNA3 & Eukaryotic expression vector & N.A & N.A & Promega \\
\hline
\end{tabular}

aKan, kanamycin; Cm, chloramphenicol; Amp, ampicillin.

bFAS, Fluorescent actin staining test.

cN.A., not applicable. 
Table 2: Oligonucleotide primers used in this study

\begin{tabular}{|c|c|}
\hline Primer & Sequence (5'-3') \\
\hline flicF & $\begin{array}{l}\text { CGTAATCAACGACTTGCAATATAGGATAACGAATCATGGCACAAGTCAT } \\
\text { TAATACCTGTGTAGGCTGGAGCTGCTTCG }\end{array}$ \\
\hline fliCR & $\begin{array}{l}\text { GCATCAGGCAATTTGGCGTTGCCGTCAGTCTCAGTTAATCAGGTTACAAC } \\
\text { GACATATGAATATCCTCCTTA }\end{array}$ \\
\hline fliC $_{\text {verify }} \mathrm{F}$ & GAGTATTTCGGCGACTAAC \\
\hline flic $_{\text {verify }} R$ & GCAGGGTTTTAATCGGACG \\
\hline flil $\mathrm{F}$ & $\begin{array}{l}\text { CCAGGAGTGGTGTAATGACCACGCGCCTGACTCGCTGGCTAACCACGCTG } \\
\text { GTGTGTAGGCTGGAGCTGCTTCG }\end{array}$ \\
\hline flil $R$ & $\begin{array}{l}\text { GGAGAGACGCTTCCCAGTCCGCGCGTTCAAAAATGCCTTGTTGCAAATAG } \\
\text { CCCATATGAATATCCTCCTTA }\end{array}$ \\
\hline flil $_{\text {verify }} \mathrm{F}$ & GCTGGCAAGAACTCTGCCG \\
\hline fili verify $_{\text {verify }} \mathrm{R}$ & GACACTGTCGGGAAAATACGC \\
\hline flis F & $\begin{array}{l}\text { GCAGTTCGAAAACAACAGTAATTCCAAGTAATCATTATTCATCGGGAGAC } \\
\text { AGGTCTGTGTAGGCTGGAGCTGCTTCG }\end{array}$ \\
\hline flis R & $\begin{array}{l}\text { GCTGGCTTTTTTCGACGAGTTGTTGCCAGGCGAAATATAAATGCGGTGCAT } \\
\text { GGTTCACATATGAATATCCTCCTTA }\end{array}$ \\
\hline fliS $_{\text {verify }} \mathrm{F}$ & CACGACCACCATCGGCAG \\
\hline flis $S_{\text {verify }} R$ & GAATCAGGCGCAGCATCGGGC \\
\hline fliCF & CATGCCATGGCACAAGTCATTAATACC \\
\hline flicR & CGCGGATCCTTAACCCTGCAGCAGAGAC \\
\hline escFF & GCTCTAGATCTGAGGGAAATTTAATG \\
\hline escFR & CCCAAGCTTTTAAAAACTACGGTTAGA \\
\hline espADB F & $\begin{array}{l}\text { GTCATGCTAAGAAAGATTATGAAGAGGTATATACATGGATACATCAACT } \\
\text { ACAGCTGTGTAGGCTGGAGCTGCTTCG }\end{array}$ \\
\hline $\operatorname{espADBR}$ & $\begin{array}{l}\text { GTTCAAGATAGTAATTAAACACTTCATCATTAAACGTATCGACCATGATC } \\
\text { AACATATGAATATCCTCCTTA }\end{array}$ \\
\hline $\operatorname{esp} A D B_{\text {verify }} \mathrm{F}$ & CCTTCTCGGGTATCGATTGTCG \\
\hline espADB $B_{\text {verify }} R$ & CGTTAAGCCCTGTTTGGTTACG \\
\hline pTrc99AF & CGGTTCTGGCAAATATTC \\
\hline
\end{tabular}

\section{References}

I. Robins-Browne RM: Traditional enteropathogenic Escherichia coli of infantile diarrhea. Rev Infect Dis 1987, 9:28-53.

2. Nataro JP, Kaper JB: Diarrheagenic Escherichia coli. Clin Microbiol Rev 1998, I I:142-201.

3. Goosney DL, Knoechel DG, Finlay BB: Enteropathogenic E. coli, Salmonella, and Shigella: masters of host cell cytoskeletal exploitation. Emerg Infect Dis 1999, 5: I-4.

4. Frankel G, Phillips AD, Rosenshine I, Dougan G, Kaper JB, Knutton S: Enteropathogenic and enterohaemorrhagic Escherichia coli: more subversive elements. Mol Microbiol I998, 30:91 I-92 I.

5. Elliott SJ, Wainwright LE, McDaniel TK, Jarvis KG, Deng YK, Lai LC, McNamara BP, Donnenberg MS, Kaper JB: The complete sequence of the locus of enterocyte effacement (LEE) from enteropathogenic Escherichia coli E2348/69. Mol Microbiol I 998 , 28: $1-4$.

6. Jerse AE, Yun J, Tall BD, Kaper JB: Genetic locus of enteropathogenic Escherichia coli necessary for the production of attaching and effacing lesions on tissue culture cells. Proc Natl Acad Sci, USA 1990, 87:7839-7843.

7. Tauschek M, Strugnell RA, Robins-Browne RM: Characterization and evidence of mobilisation of the LEE pathogenicity island of rabbit-specific strains of enteropathogenic Escherichia coli. Mol Microbiol 2002, 44: I533-I550.

8. Daniell S, Takahashi N, Wilson R, Friedberg D, Rosenshine I, Booy FP, Shaw R, Knutton S, Frankel G, Aizawa SI: The filamentous type III secretion translocon of enteropathogenic Escherichia coli. Cell Microbiol 200I, 3:865-87I.

9. Deng W, Puente JL, Gruenheid S, Li Y, Vallance BA, Vazquez A, Barba J, Ibarra JA, O'Donnell P, Metalnikov P, Ashman K, Lee S, Goode D Pawson T, Finlay BB: Dissecting virulence: systematic and functional analysis of a pathogenicity island. Proc Natl Acad Sci, USA 2004, I $01: 3597-3602$

10. Cornelis GR, Van Gijsegem F: Assembly and function of type II secretory systems. Ann Rev Microbiol 2000, 54:735-774.
II. Kubori T, Matsushima Y, Nakamura D, Urali J, Lara-Tejero M, Sukhan A, et al.: The invasion-associated type III protein secretion system forms a supramolecular structure on envelope of Salmonella typhimurium. Science 1998, 280:602-605.

12. Galan JE, Collmer A: Type III secretion machines: bacterial devices for protein delivery into host cells. Science 1999 , 284: | 322- I328.

13. Macnab RM: How bacteria assemble flagella. Ann Rev Microbiol 2003, 57:77-100.

14. Wilson RK, Shaw RK, Daniell S, Knutton S, Frankel G: Role of EscF a putative needle complex protein, in the type III protein translocation system of enteropathogenic Escherichia coli. Cell Microbiol 2001, 3:753-762.

15. Delahay RM, Knutton S, Shaw RK, Hartland EL, Pallen MJ, Frankel G: The coiled-coil domain of EspA is essential for the assembly of the type III secretion translocon on the surface of enteropathogenic Escherichia coli. J Biol Chem 1999, 274:35969-35974.

16. Pallen MJ, Beatson SA, Bailey CM: Bioinformatics analysis of the locus for enterocyte effacement provides novel insights into type-III secretion. BMC Microbiology 2005, 5:9.

17. Minamino T, Macnab RM: Interactions between components of the Salmonella flagellar export apparatus and its substrates. Mol Microbiol 2000, 35:1052-1064.

18. Crepin VF, Shaw R, Abe CM, Knutton S, Frankel G: Polarity of Enteropathogenic Escherichia coli EspA filament assembly and protein secretion. I Bacteriol 2005, | 87:288|-2889.

19. Yonekura K, Maki-Yonekura S, Namba K: Complete atomic model of the bacterial flagellar filament by electron cryomicroscopy. Nature 2003, 424:643-650.

20. Daniell S, Kocsis E, Morris E, Knutton S, Booy FP, Frankel G: 3D structure of EspA filaments from enteropathogenic Escherichia coli. Mol Microbiol 2003, 49(2):30I-308.

21. Deng W, Li W, Hardwidge PR, Frey EA, Pfuentzer RA, Lee S, Gruenheid S, Strynadka NCJ, Puente JL, Finlay BB: Regulation of type III secretion hierarchy of translocators and effectors in attach- 
ing and effacing bacterial pathogens. Infect Immun 2005, 73:2135-2146

22. Sekiya K, Ohishi M, Ogino T, Tamano K, Sasakawa C, Abe A: Supermolecular structure of the enteropathogenic Escherichia coli type III secretion system and its direct interaction with the EspA-sheath-like structure. Proc Natl Acad Sci, USA 200I, 98:11638-11643.

23. Giron JA, Torres AG, Freer E, Kaper JB: The flagella of enteropathogenic Escherichia coli mediate adherence to epithelial cells. Mol Microbiol 2002, 44:36I-379.

24. Zhou X, Giron JA, Torres AG, Crawford JA, Negrete E, Vogel S, Kaper JB: Flagellin of enteropathogenic Escherichia coli stimulates interleukin-8 production in T84 cells. Infect Immun 2003, 71:2120-2I29.

25. Blumer C, Kleefeld A, Lehnen D, Heintz M, Dobrindt U, Nagy G, Michaelis K, Emody L, Polen T, Rachel R, et al.: Regulation of type I fimbriae synthesis and biofilm formation by the transcriptional regulator LrhA of Escherichia coli. Microbiology 2005, I 5 I:3287-3298.

26. Claret L, Calder SR, Higgins M, Hughes C: Oligomerization and activation of the Flil ATPase central to bacterial flagellum assembly. Mol Microbiol 2003, 48(5): I 349-1355.

27. Aldridge $\mathrm{P}$, Hughes KT: Regulation of flagellar assembly. Cur Opin Microbiol 2002, 5: 160-165.

28. Deng W, Puente JL, Gruenheid S, Li Y, Vallance BA, Vazquez A, Barba J, Ibarra JA, O'Donnell P, Metalnikov P, et al.: Dissecting virulence: systematic and functional analyses of a pathogenicity island. Proc Natl Acad Sci USA 2004, I 0 I:3597-3602.

29. O'Connell CB, Creasey EA, Knutton S, Elliott S, Crowther LJ, Luo W, Albert MJ, Kaper JB, Frankel G, Donnenberg MS: SepL, a protein required for enteropathogenic Escherichia coli type III translocation, interacts with secretion component SepD. Mol Microbiol 2004, 52:1613-1625.

30. Khan MA, Bouzari S, Ma C, Rosenberger CM, Bergstrom KS, Gibson DL, Steiner TS, Vallance BA: Flagellin-dependent and -independent inflammatory responses following infection by enteropathogenic Escherichia coli and Citrobacter rodentium. Infect Immun 2008, 76: I4I 0-1422

31. Sharma R, Tesfay S, Tomson FL, Kanteti RP, Viswanathan VK, Hecht G: Balance of bacterial pro- and anti-inflammatory mediators dictates net effect of enteropathogenic Escherichia col on intestinal epithelial cells. Am J Physiol, Gastro Liver Physiol 2006 290:G685-G694

32. Viala J, Chaput C, Boneca IG, Cardona A, Girardin SE, Moran AP, Athman R, Memet S, Huerre MR, Coyle AJ, DiStefano PS, Sansonetti PJ, Labigne A, Bertin J, Philphott DJ, Ferrero RL: NodI responds to peptidoglycan delivered by the Helicobacter pylori cag pathogenicity island. Nature Immunol 2004, 5: I I66-74.

33. Pallen MJ, Matzke NJ: From The Origin of Species to the origin of bacterial flagella. Nat Rev Microbiol 2006, 4:784-790.

34. Miao EA, Miller SI: A conserved amino acid sequence directing intracellular type III secretion by Salmonella typhimurium. Proc Natl Acad Sci USA 2000, 97:7539-7544.

35. Lee SH, Galan JE: Salmonella type III secretion-associated chaperones confer secretion-pathway specificity. Mol Microbiol 2004, 5 I:483-495

36. Young GM, Schmiel DH, Miller VL: A new pathway for the secretion of virulence factors by bacteria: the flagellar export apparatus functions as a protein-secretion system. Proc Natl Acad Sci USA 1999, 96:6456-646I.

37. Young BM, Young GM: YpIA is exported by the Ysc, Ysa, flagellar type III secretion systems of Yersinia enterocolitica. J Bacteriol 2002, 184: 1324-1334.

38. Ehrbar K, Winnen B, Hardt WD: The chaperone binding domain of SopE inhibits transport via flagellar and SPI-I TTSS in the absence of InvB. Mol Microbiol 2006, 59:248-264.

39. Miao EA, Alpuche-Aranda CM, Dors M, Clark AE, Bader MW, Miller $\mathrm{SI}$, Aderem A: Cytoplasmic flagellin activates caspase-I and secretion of interleukin I $\beta$ via Ipaf. Nature Immunol 2006 7:569-575

40. Ruchaud-Sparagano MH, Maresca M, Kenny B: Enteropathogenic Escherichia coli (EPEC) inactivate innate immune responses prior to compromising epithelial barrier function. Cell Microbiol 2007, 9: | $909-2 \mid$
4I. Andersen-Nissen E, Smith KD, Strobe KL, Barrett SL, Cookson BT, Logan SM, Aderem A: Evasion of Toll-like receptor 5 by flagellated bacteria. Proc Natl Acad Sci USA 2005, 102:9247-9252.

42. Kenny B, Abe A, Stein M, Finlay BB: Enteropathogenic Escherichio coli protein secretion is induced in response to conditions similar to those in the gastrointestinal tract. Infect Immuny 1997, 65(7):2606-26|2.

43. Xicohtencatl-Cortes J, Lyons S, Chaparro AP, Hernandez DR, Saldana Z, Ledesma MA, Rendon MA, Gewirtz AT, Klose KE, Giron JA: Identification od proinflammatory flagellin proteins in supernatants of Vibrio cholerae $O I$ by proteomics analysis. Mol Cell Proteom 2006, 5:2374-2383.

44. Molloy MP, Herbert BR, Slade MB, Rabilloud T, Nouwens AS, Williams KL, Gooley AA: Proteomic analysis of the Escherichia coli outer membrane. Eur J Biochem 2000, 267:287|-288I.

45. Datsenko KA, Wanner BL: One-step inactivation of chromosomal genes in Escherichia coli K-I 2 using PCR products. Proc Natl Acad Science, USA 2000, 97:6640-6645.

46. Knutton S, Baldwin T, Williams PH, McNeish AS: Actin accumulation at sites of bacterial adhesion to tissue culture: basis of a new diagnostic test for Enteropathogenic and Enterohaemorrhagic Escherichia coli. Infect Immun 1989, 57: 1290-1298.

47. Levine MM, Edelman R: Enteropathogenic Escherichia coli of classic serotypes associated with infant diarrhea: epidemiology and pathogenesis. Epidemiol Rev 1984, 6:3I-5I.

48. Lee SF, Kelly M, McAlister A, Luck SN, Garcia EL, Hall RA, RobinsBrowne RM, Frankel G, Hartland EL: A C-terminal class I PDZ binding motif of Espl/NleA modulates the virulence of attaching and effacing Escherichia coli and Citrobacter rodentium. Cell Microbiol 2008, 10:499-513.

49. Amann $\mathrm{E}$, Ochs $\mathrm{B}, \mathrm{Abel} \mathrm{KJ}$ : Tightly regulated tac promoter vectors useful for the expression of unfused and fused proteins in Escherichia coli. Gene 1988, 69:301-315.

Publish with Biomed Central and every scientist can read your work free of charge

"BioMed Central will be the most significant development for disseminating the results of biomedical research in our lifetime. "

Sir Paul Nurse, Cancer Research UK

Your research papers will be:

- available free of charge to the entire biomedical community

- peer reviewed and published immediately upon acceptance

- cited in PubMed and archived on PubMed Central

- yours - you keep the copyright
BioMedcentral 